\title{
A Task-Based Approach to Motivate Speaking in the ESL Classroom
}

\author{
Rathnasena, U. \\ upeksha.r@sliit.lk \\ English Language Teaching Unit (ELTU), Faculty of Humanities and Sciences, SLIIT, Malabe, \\ Sri Lanka
}

\begin{abstract}
The speaking competency of students learning General English at Tertiary Educational Institutes (TEIs) has become a primary concern of many academics and policy makers. In such a context, this paper investigates the implications of incorporating a task-based speaking component in the English as a Second Language (ESL) curriculum at tertiary level. The sample cohort comprises of post Advanced Level students studying General English at a private institute. An identical speaking task was administered, first without scaffolding and later with scaffolding to observe students' performance. It was observed that when a speaking activity is assigned, learners have the tendency to visualize it in L1 and convert it to L2. In a case where scaffolding items such as, notecards and strips are not allowed, learners memorize the lines or utterances and enact the given speaking task. Consequently, their discourse is impeded as they struggle for better vocabulary as well as sentences. Insights of the students' need, and their feedback led the institute allocate extra time weekly for speaking. It is recommended that more task-based speaking activities are introduced to the institute's ESL: Speaking Curriculum.
\end{abstract}

Keywords: L1 Speaking, L2 Speaking, Scaffolding, TBLT, TEI

\section{Introduction}

Teaching English has been an intensively researched area in the Sri Lankan context. From post-colonial times, English Language research paradigms have shifted, and pedagogical and andragogic approaches have been revised, restructured, and transformed by different national initiatives like "English as a life skill". Nevertheless, the oral proficiency of school leavers and the job seekers is alarmingly poor and different segments of society including academic bodies and potential employers have expressed concern over this matter. As oral proficiency is not tested at national level exams, the majority of students attend private institutes for English language education. However, these different institutes have various curricular and adopt independent teaching approaches. Even though there are many trainers of English language all around the country, the common grievance articulated by the students and teachers alike is the oral incompetence of the students. The same scenario was observed at the present institute where the students learn for a Diploma in English. The majority of the population struggle when required to speak in the classroom and they are very reticent in the class and more often than not opt for the mother tongue as the main medium of communication. This situation has nearly made "speaking in English - an impossibility." However, during the course of studies, a very interesting feature was observed in the speaking of the students in the classroom. In fact, the students' production of the 
L2 utterances was more grammatically accurate whenever the students were given a "grace period" or a "preparation time". Conversely the same students were identified to be making the most fundamental errors and exhibited more reticence when the "preparation Time" was not allowed by the teacher. Therefore, it became quite pertinent to investigate this intriguing gap observed in this General English classroom.

This study will be significant in providing insights to ESL teachers in their reflective practices. For example, it will be beneficial to the teachers when identifying the learning gaps in the learners especially in "speaking". As a result, they are expected to be better reflective practitioners focusing on the learners' weaknesses and designing remedial pedagogical activities in overcoming such issues. By understanding the needs of the ESL learners, the teachers are also expected to provide more scaffolding which would make them more fluent. Furthermore, it is expected that the findings of this research will be significant in providing recommendations on how to design speech fronted activities which will in turn improve the oral fluency of the ESL learners. This study will also be helpful to the fellow Sri Lankan researchers in providing implications, insights into the unexplored domains in ESL teaching with the primary focus on improving the oral fluency which is a very formidable challenge to the Sri Lankan English Learners irrespective of the innumerable number of institutes offering General English classes. More importantly, it is expected that this research will apprise curriculum designers in deciding whether a paradigm shift is required in the ESL corpus and the importance of improvisation and establishing strong links with the teacher community in a holistic manner.

There is a plethora of concepts and theories available in the ESL discipline that define speaking even though there is very limited empirical research on the relationship between speaking and writing competencies of ESL learners (Ovando, et el., 2003). First, one must take into account the concept of "Speaking". It is "the process of building and sharing meaning through the use of verbal and non-verbal symbols, in a variety of contexts" (Chaney, 1998). In the ESL context, a learner should be able to perform the above in the similar manner as one would do in the native language. Nunan (2003) conceptualizes "Speaking in the ESL context" by identifying the following components:

- Produce the English speech sounds and sound patterns

- Use word and sentence stress, intonation patterns and the rhythm of the second language.

- Select appropriate words and sentences according to the proper social setting, audience, situation and subject matter.

- Organize their thoughts in a meaningful and logical sequence.

- Use language as a means of expressing values and judgments.

Furthermore, Kroll (1981) constructed a model of Speaking-Writing relationship in L1 for children grounded on the key bases namely, Preparation, Consolidation, Differentiation and Integration. According to this model, Kroll concludes that there is a very strong correlation between these two modalities and that children's writing proficiency in L1 develops on the basis of their speaking proficiency. In most of the cases, L1 speaking proficiency precedes L1 writing proficiency. However, in the L2 context, circumstances and empirical evidence can be entirely different and discreet as the amount of research done is noticeably inadequate. Williams (2008) points out that Kroll's theory for L1 Speaking and Writing 
correlation cannot be directly applied to the L2 context as cognitive and social factors may exert an influence on the L2 acquisition in the ESL scenario. Weissberg (2002) proposes that the written modality can be stronger than the Speaking modality after studying five Spanish ESL learners whose written productions were characterized by higher levels of accuracy and syntactic innovation which is the use of new morphological items. Interestingly, the same learners did not exhibit the same oral fluency claims Weissberg. Nevertheless, there he observed varying degrees of oral fluency even among the five students he studied and concluded this phenomenon to be an asymmetrical development for the binary modalities. One of the very few studies pertaining to the development and the causal relationship between speaking \& writing modalities was conducted by Mochizuki (2008). Mochizuki (2008) conducted research into the proficiency levels of speaking and writing modalities by administering speaking and writing tasks for a group of 81 ESL university students. His finding was that the students used more lowfrequency words in Speaking than in Writing. However, the findings of Mochizuki cannot be generalized into other contexts as he did not use the identical task for both modalities hence resulting in the task effect scenario. One other study which investigated the modality difference was Kormos $\&$ Trebits (2012) study.

Another seminal theory in L2 oral production is the model conceptualized by Levelt (1989). In his perspective, he invented a prototype based on the three pillars namely, conceptualizer, formulator, and articulator. In his view, all the three elements play a vital role in the processing of a learner's L2. The conceptualizer creates the message while the formulator is responsible for shaping the grammatical and phonological outlook of the message; and finally, the articulator conveys the message.
In a survey conducted in Hongkong which has more relevance to the Sri Lankan context, since it is an Asian country, Hyland (1997) concluded that the central problems pertaining to ESL university students stem from the productive skills of writing and speaking. This presents a similar scenario to the one that is being investigated in this study where the learners are negotiating the two modalities to communicate in English which is the target language.

Furthermore, Richards (2006) identified speaking activities in three different tiers. They are talk as interaction, transaction, and performance. The tier which concerns this study is Interaction which describes "conversation" in the form of social interaction on which the activity was based in this study.

However, the main objective of this study was to analyze different aspects of narrative tasks whereas modality difference was studied conjunctively. Their finding was that learners used a wider range of vocabulary in the written form than in Speaking but noted similar grammatical complexity in both modalities.

In addition to the above-mentioned modalitybased theories, one other concept which is closely related to this study's pedagogical significance is Scaffolding. This notion was initially developed by the Russian Psychologist, Lev Vygotsky even though he did not use the term "Scaffolding". He introduced the concept of Zone of Proximal Development(ZPD).ZPDisdefinedas the "distance between the child's actual developmental level as determined by independent problem-solving and the higher level of potential development as determined through problem-solving under adult guidance and in collaboration with more capable peers" (Vygotsky, 1978). According to him a learner is capable of bridging the gap between the 
actual and the potential depending on the support and the resources available for him/her in the teaching/learning environment. This notion was later linked to ZPD and became a key element in the modern language classroom. Many proponents of Scaffolding can be identified in later studies.

"Scaffolding refers to providing contextual supports for meaning through the use of simplified language, teacher modeling, visuals and graphics, cooperative learning and hands-on learning" (Ovando, Collier, \& Combs, 2003). Three aspects of Scaffolding have been identified as illustrated in Figure 1.

\section{Figure 1.}

\section{Three aspects of Scaffolding}

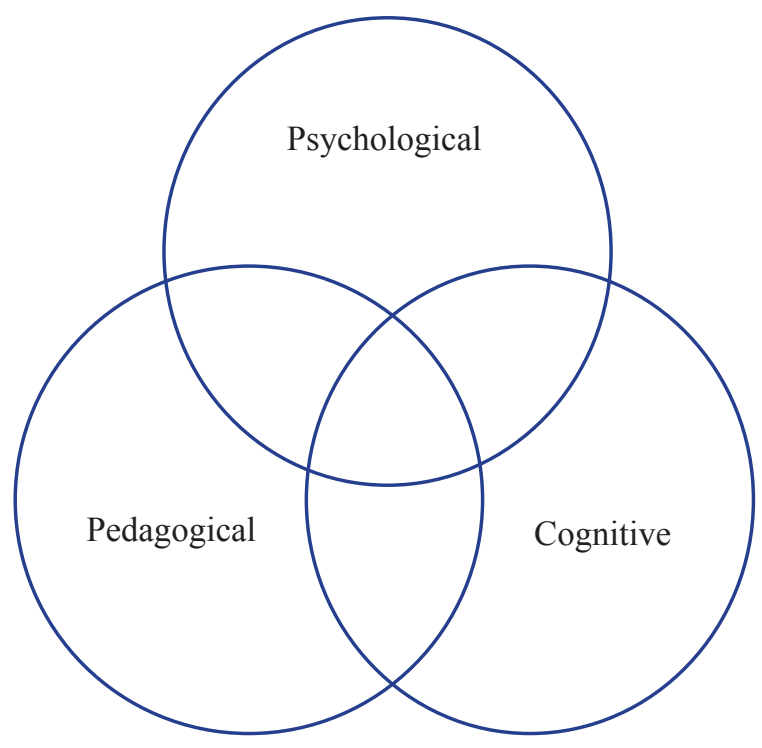

These 3 aspects are seen as integrated components and are considered to be equally important in ZPD and according to Diaz-Rico \& Weed (2002) "The teacher of second language learners has to facilitate that support" and "as students become more proficient, the scaffold is gradually removed"

The primary objective of the study is to investigate the implications of incorporating a task-based speaking component to the General English curriculum at a TEI. It will provide implications, insights into the unexplored domains in ESL teaching with the primary focus on improving the speaking proficiency. The secondary objective is to provide insights to ESL teachers for their reflective practices. For example, it will be beneficial to the teachers when identifying the learning gaps in the learners especially in "speaking. By understanding the needs of the ESL learners, teachers can provide more scaffolding via focusing on the learners' needs and designing remedial pedagogical activities.

\section{Materials and Methods}

To investigate the differences between the production/performance in the two modalities; namely speaking and writing, the identical task was administered with two different approaches. The first approach was to administer the task which was a role play without any scaffolding in the form of role cards or dialogue cards or scripts. Subsequently, the same task was administered with Scaffolding in the form of role cards or dialogue cards or typescripts. The identical task was used in order to minimize the "task effect" on the results so that falsifications will be nullified.

A sample of 30 students was given a role play centred upon socialization in the day-to-day context. The role plays were video recorded and transcribed verbatim. The scripts used by the same participants for the second phase were collected. The videos were watched, and the transcripts were read. Subsequently, the video transcripts were compared with the scripts (scaffolding) used by participants for 
the second phase. The transcripts were marked with comments and specific descriptive chunks called “open coding” (Merriam, 2009). Thereafter, a process of clustering was done where the data was narrowed to "thematic units" and "core categories" to shed light on the patterns/differences surfacing in the data.

\section{Results and Discussion}

The video tapes/transcriptions and scripts were analysed in the following aspects.

\section{Vocabulary range}

ESL learners struggle with lack of vocabulary, the participants in this study also exhibited the same characteristic. However, they exhibited a wider range of vocabulary and density when preparation time was given. The incongruities in vocabulary choice were shown in the following ways.

\section{Language transfer}

Language transfer or L1 interference is a very common occurrence in the ESL context. It is the scenario where the learners of a second or a foreign language used the more familiar mother tongue structures in the learning process of the second language which subsequently hinders accurate L2 communication as old habits of the first language continue to be present in an intimidating way while the new habits (the second language) are being learned. In many second language learners, L1 inference acts as a negative agent rather than a productive tool for Second Language Acquisition. (SLA). In other words, there must be a process of "unlearning" before the habits/practices of the second language are being learnt. However, what was observed here was that while learning a second language a learner inevitably uses the L1 which leads to the scenario of L1 interference. Extensive research has been conducted on the L1 interference on the target language (L2). Different hypotheses and theories have been presented by a gamut of linguists who have attempted to analyze this interesting linguistic phenomenon.

\section{Circumlocution}

Circumlocution is a communication strategy very commonly used by second language learners in the communication process in the event of linguistic inadequacy in the second language. In brief, when they lacked the precise word for a particular English word, they opted to use the Sinhala word (native word) in recounting or defining a concept instead of saying or writing the specific words. This sample of students has used circumlocution in the following main ways.

- Using familiar vocabulary (Example: using the word teacher when they didn't know the word lecturer)

- Using synonyms (Example: using the word small instead of minute)

- Using categories (furniture, jobs, and clothing). (Example: using the word type of furniture when the word closet was not known)

- Trying alternative ways of conveying the message.

Describing the notion by explaining the sage, location, importance, relevance etc. 


\section{Approximation}

It is a strategy frequently used by leaners to describe a term in the second language which is in this case English with the help of another word which is closely related to the original term. This sample even used phrases such as 'kind of', 'a sort of', 'almost like' as a word which closely resembles the target word.

Examples:

- "A sort of a hole with water" to mean "puddle".

- "Almost like a long bus" to mean "coach"

- "Kind of a very big prawn" to mean "lobster".

However, at times approximation has a tendency to deliver the incorrect message since these approximations seem to use certain incorrect terms which share several semantic features. As shown above, the third example used by these learners, does not exactly convey the correct meaning which in fact leads to certain semantic misunderstandings.

\section{Grammatical Accuracy}

The accuracy level of the second phase was higher than the first phase owing to the grace period given. Nevertheless, it was found that the syntactic complexity is similar in both phases. This can be crystalized in terms of distinction between language competence and strategic competence (Choneg \& Burk, 1998). Language competence consists of organizational competence (e.g., grammatical, and textual competence) which enables the L2 speaker to communicate effectively with the best selection of syntactic structures.
The most common errors which were observed in phase 1 which were rectified by students in phase 2 were,

\section{The omission of $S$ in the third person singular}

In the role plays and skits observed in this study, the students were able to rectify several errors. "The omission of's' in the third person singular is one of the most easily rectified by these learners.

In English, in the present tense, a verb changes its form only when the subject is third-person singular (he/she/it). Interestingly, these participants omitted the "s" in phase one but were able to correct it in phase two. The researcher's observation is that the students' inhibitions towards English, the lack of competency and the infrequency of L2 usage apparently led to these types of errors. However, once preparation time is provided as it allows them a grace period of formulating grammatically correct sentences which is not provided in Phase 1.

\section{Using the past form of verbs in the making of simple passive instead of past perfect.}

This is another prominent error which was rectified by the participants in Phase 2 . Example: "The plane was flew by my brother" instead of "The plane was flown by my brother" was one utterance used by a participant. As mentioned in the previous explanation the participants corrected this particular error after discussing with the fellow participants. They discussed with the fellow participants and adjusted the forms in the passive forms and did phase 2 in a more accurate manner. 
Nevertheless, compared to the error correction percentage of the "omission of ' $s$ ' in the third person singular", the accuracy rate is much lower.

\section{Confusion between present perfect tense and past tense}

This is another recurrent error which was observed by the researcher. Generally, students readily grasp that the present perfect tense is formed with have or has plus the past participle. Even the past tense formation is internalized by the students in a relatively successful manner. However, in this study the participants rectified more than $50 \%$ of the errors committed in Phase 1. Seemingly, their difficulty was recalling the past tense form and differentiation between present perfect tense and past tense scenarios.

\section{Omission of articles (a/an/the)}

Omission of articles (a/an/the) is the most recurrent error observed in this study and rectified by the participants in Phase 2 .

Some examples were.

* "I had (article missing) exam."

* "We had (article missing) party".

* "My mother is (article missing)

homemaker".

This error correction had the same pattern as the previous error corrections since it was also corrected in Phase 2. This error can be caused by the absence of such a feature in the participants' native language which is Sinhala. In fact, in Sinhala one does not add an extra element unlike in English to mean a/an/the as it is embedded in their noun phrases. The participants rectified this error subsequently as they recall the grammar rules within the preparation time given.

\section{Conclusions and Suggestions}

Language learners employ different types of strategies in the process of learning. They are cognitive, metacognitive, and socio affective strategies. Even in the ESL context, these strategies are consciously or unconsciously utilized by the learners. However, in the event of speaking, the appropriacy of these strategies used by students is of great relevance as speaking is the most difficult skill to master for the ESL speakers.

This sample of students performed better when they used writing as a scaffolding which exemplifies the use and emphasis of the effect of writing on speaking. Therefore, rather than discouraging the habit of writing before speaking, it may be useful to motivate them to write more as it would eventually affect their oral fluency in a positive way.

The classroom activities must be modified and tailored in a speech fronted manner with more tasks requiring spontaneous language production within the grace period. A practice like Journal Writing can be incorporated into the tasks as it broadens learner vocabulary. Since Journal Writing is not evaluated the tense/stress factor is naturally eliminated from the L2 learners' which encourages a low affective filter leading to enhanced L2 production and acquisition. This can be adopted as an effective strategy for enhancing oral fluency of the ESL students in the Sri Lankan classrooms. 


\section{Acknowledgement}

The support provided by my students who were the sample of this research study is heartily appreciated.

\section{References}

Chaney, A. L., \& Burk T. L. (1998). Teaching Oral Communication in Grades $\mathrm{K}-8$. Boston.

Diaz-Rico, L.T., \& Weed, K.Z. (2002). The crosscultural, language, and academic development handbook: A complete K-12 reference guide (2nd ed.). Boston: Ally \& Bacon.

Hyland, K. (1997). Is EAP necessary? A survey of Hong Kong undergraduates. AsianJournal of English Language Teaching, 7, 77-99.

Kormos, J., \& Trebits, A. (2012). The role of task complexity, modality, and aptitude in narrative task performance. Language Learning, 62(2), 439-472.

Kroll, B. M. (1981). Speaking-Writing Relationships: Connections and Contrasts. National Council of Teachers of English, Urbana, Ill.1.

Levelt, W. (1989). Speaking: From Intention to Articulation. Cambridge, MA: The MIT Press.

Merriam, S. B. (2009). Qualitative research: A guide to design and implementation. San Francisco, CA: Jossey-Bass.
Mochizuki, M. (2008). Speaking to writing ni okeru sanshutsu goi no chigai [The difference of productive vocabulary in speaking and writing]. Reitaku Review, 14, 3-13.

Nunan, D., (2003). Practical English Language Teaching. NY:McGraw-Hill.

Ovando, C., Collier, V., \& Combs, M. (2003). Bilingual and ESL classrooms: Teaching multicultural contexts ( 3 rd ed.). Boston: McGraw-Hill.

Richards, J. C. (2006). Developing classroom speaking activities: From theory to practice. Guidelines, (RELC, Singapore), 28, 3-9.

Vygotsky, L. (1978). "Interaction between learning and development." (pp. 79-91). In Mind in Society. (Trans. M. Cole). Cambridge, MA: Harvard University Press.

Weissberg, B. (2000). Developmental relationships in the acquisition of English syntax: writing vs. speech. Learning and Instruction, 10, 37-53.

Weissberg. R (2006). Connecting speaking \& writing in second language writing instruction. Ann Arbor: The University of Michigan Press.

Williams, J. (2008). The speaking-writing connection in second language and academic literacy development. The oral/ literate connection: Perspectives on L2 10-25. 